\title{
Investigation and Research on the Application of Mobile Learning Tools in Higher Vocational College Students
}

\author{
Zhang Cheng-xia, Wu Hong, LI Cheng-zhong* \\ Jiangsu Agri-animal Husbandry Vocational College, China
}

*Corresponding Author: LI Cheng-zhong, Jiangsu Agri-animal Husbandry Vocational College, China

\begin{abstract}
In order to find out the higher vocational students' possession and understanding of mobile learning tools, the authors adopt the method of questionnaire survey for this survey. The results show that almost all students have mobile learning tools, but only $22.6 \%$ of them know mobile learning tools well. According to the use of mobile learning tools, although students use mobile tools every day, but mainly for entertainment, telephone calls, etc., accounting for more than 96\%, and as a learning tool used only $29.1 \%$. According to the utilization of mobile learning resources, $82.1 \%$ of the students think that teachers can get more learning information and stimulate learning interest when using mobile learning equipment in class, $67.2 \%$ of the students think that mobile learning can improve learning efficiency, $97.3 \%$ of the students think that mobile learning can broaden professional knowledge. The authors suggest that students should be properly guided to use mobile learning tools in the study and expansion of professional knowledge, to give full play to its advantages of convenience, easy access to resources, and to better serve students' learning.
\end{abstract}

Keywords: Higher vocational students; mobile learning tools; application; survey

\section{INTRODUCTION}

With the development of mobile communication equipment, mobile learning, as a new learning method, has attracted more and more people's attention. Its characteristics are learning convenience, teaching individuation, interaction richness, context relevance, etc. ${ }^{[1]}$. At the same time, in recent years, with the continuous expansion of wireless network coverage and the continuous improvement of smart phone functions. Smartphone has become the main tool for college students to learn independently. It shows its unique advantages in supporting students' learning ${ }^{[2,3]}$ and has won the favor of many learners. The mobile learning tool also expands and extends the classroom through fragmented seamless learning before and after class, realizing the integration of multiple dimensions of learning, providing learners with a broad, flexible and highly creative learning space, which truly embodies the principle that learners are the center ${ }^{[4,5]}$.

Due to the uneven quality of students, higher vocational colleges, compared with ordinary universities, the teaching process in higher vocational colleges is more difficult to control, and the traditional teaching methods encountered many problems in teaching. Can mobile learning improve and promote students' learning in Higher Vocational Colleges? What is the current situation of higher vocational college students to use mobile learning? This paper makes a questionnaire survey on the students of Taizhou Vocational College, analyzes the situation of their possession and understanding of mobile learning tools, the use of mobile learning tools and the effect of using mobile learning tools to learn, and it grasps the cognition of higher vocational students on mobile learning tools and the application in curriculum learning. It provides a reference for students to make better use of mobile learning tools and draw up correct guidance strategies.

\section{Mobile Learning AT HoMe ANd AbroAd}

The mobile learning research started in 1994 with the Wireless Andrew research project of Carnegie Mellon University in the United States. The project lasted for three years. Finally, it provided highspeed wireless connections covering the entire campus for teachers, students and managers through the wireless infrastructure construction [6]. At present, the research on mobile learning abroad is mainly concentrated in some economically advanced countries in Europe and North America. Some earlier researches on mobile learning have been carried out for more than 10 years [7]. 
The mobile learning in China started relatively late. The earliest research was in 2000 , and the Desmond Keegan, an international distance educator, introduced the concept of mobile learning to China for the first time in his academic report entitled "From e-Learning to m-Learning" in Shanghai. He said that mobile learning represents "the future of learning". It has opened the prelude of mobile learning in China's research, development and application [8]. Because learners can learn anything they want to learn at any time, anywhere, in any way, mobile learning has attracted wide attention in China. In December 2001, the Ministry of Education Higher Education Department issued a notice on the theoretical and practical research projects of "mobile education", and it began to explore the application of mobile learning in Chinese universities from theory to practice.

\section{DESIGN AND IMPLEMENTATION OF SURVEY RESEARCH}

We mainly adopt the method of questionnaire survey for this survey. The subjects were students from several Vocational Colleges in Taizhou City, Jiangsu Province, mainly students from Jiangsu Agricultural and Animal Husbandry Vocational College and Taizhou Vocational and Technical College. The questionnaire is designed from three aspects: the ownership and understanding of mobile learning tools, the use of mobile learning tools and the effect of using mobile learning tools to learn. A total of 400 questionnaires were distributed, 376 valid questionnaires were collected, and the effective rate of the questionnaire was 94\%. Questionnaire data were processed by Excel software.

\section{ANALYSIS OF SURVEY RESUlTS}

\subsection{The Possession and Understanding of Mobile Learning tools in Higher Vocational Colleges}

\subsubsection{About Mobile Learning Tools Owned by Vocational Students}

Because college campuses are generally far away from home, now every student has at least one mobile phone, and the price varies from nearly 1000 yuan to several thousand yuan, so that students can contact their parents at any time. Figure 1 shows that the most mobile device currently owned by students is smart phone, which is $99.1 \%$, followed by laptops, which is $60.9 \%$. Desktop computers and tablet computers are the least, which are $1.6 \%$ and $1.2 \%$ respectively, and the student without any equipment is 0 . It shows that the smart phones are the first choice for mobile learning in the hands of students, followed by notebook computers.

\subsubsection{Degree of Vocational Students' Understanding for Mobile Learning Tools}

Figure 2 shows that only $22.6 \%$ of vocational college students know mobile learning tools very well, $50.5 \%$ of them generally know mobile learning tools, while $26.9 \%$ of students have not heard of mobile learning tools. This shows that although college students use modern mobile devices such as smart phones, tablets and so on, they know little about the relationship between these tools and mobile learning.

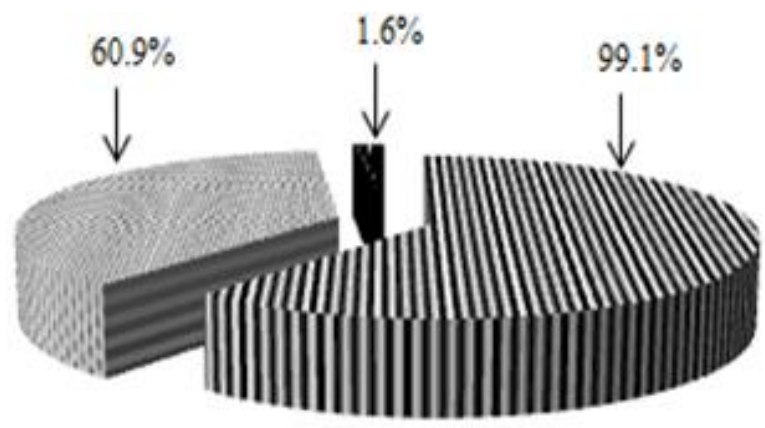

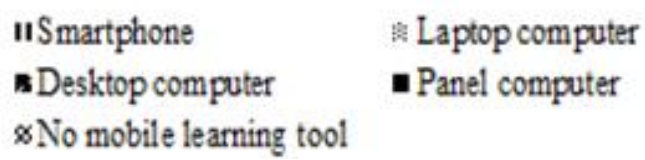

Figure1. About mobile learning tools owned by Vocational Students

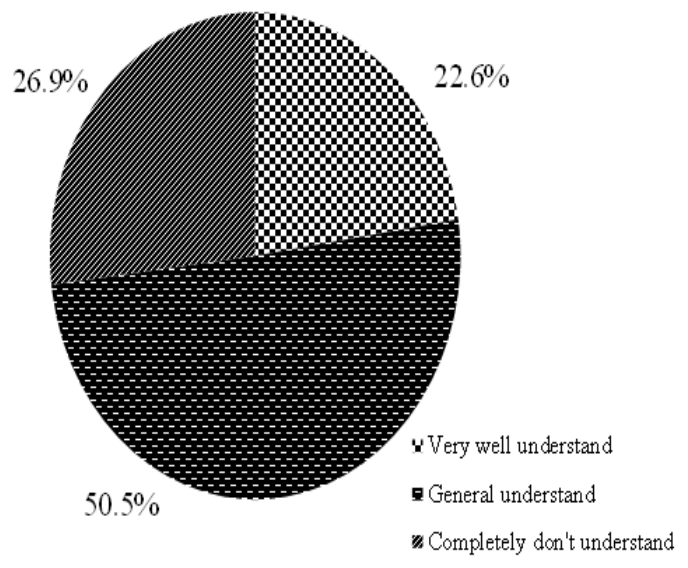

Figure2. About mobile learning tools owned by Vocational Students 


\subsection{Vocational Students' Use of Mobile Learning Tools}

Compared with middle schools, vocational students have plenty of spare time. Mobile devices, especially smart phones and laptop, are portable, and fast in updating information. They have become the main mobile tools used by most students after class. Figure 3 shows that $98.7 \%$ of students use mobile tools frequently, $1.3 \%$ occasionally, and no student has never used mobile tools.

As can be seen from Figure 4, the main purpose of students using mobile devices is to make phone calls and videos, entertainment (playing games, watching movies and TV plays, etc.), social applications, consumer payments, etc. Among them, $100.0 \%$ are used to make phone calls and videos, 96.2\% are used to play games, TV shows and entertainment., and $94.2 \%$ are used to socialize. $6 \%$, $95.7 \%$ for consumer spending, $29.1 \%$ only for learning tools and $3.3 \%$ for others.

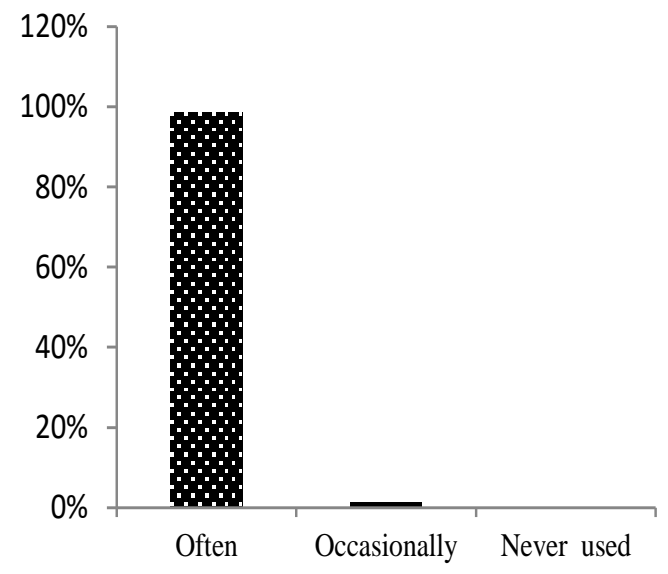

Figure3. Frequency of students' use of mobile devices

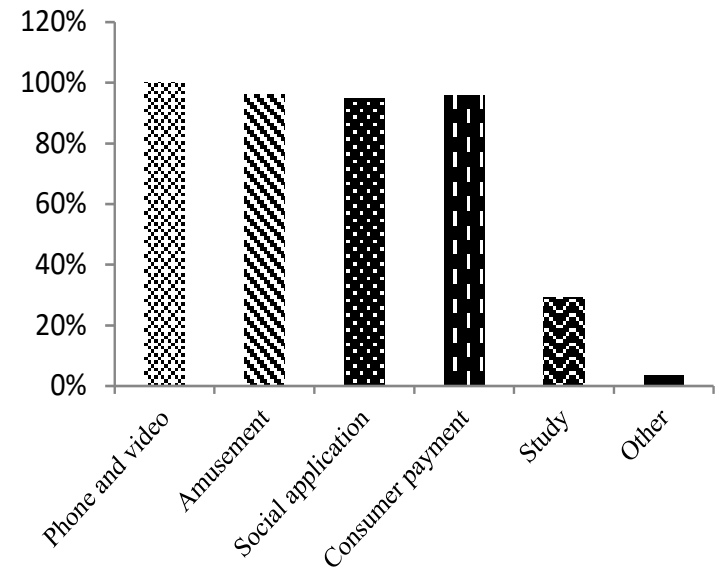

Figure4. Frequency of students' use of mobile devices

\subsection{Higher Vocational Students' Utilization Effect of Mobile Learning Resources}

\subsubsection{Usage Mode of Resources}

In the process of investigation, there are many ways for students to use learning resources, such as downloaded to the mobile phone cloud, notebook online and local. Because of the current mobile devices (smart phones, laptops, etc.) storage space is larger, coupled with that all schools have full coverage of wireless networks, most students will choose to download to the cloud. The number reached $87.7 \%$. When learning related content, it is directly retrieved from the cloud and downloaded to local $79.8 \%$, such as downloaded to the mobile phone cloud, notebook online and local, due to the current mobile devices (smartphones, laptops, etc.) storage space is larger, coupled with almost all the school wireless network coverage, most students will choose to download to the cloud. The ratio is $87.7 \%$. When learning related content, it is directly retrieved from the cloud and downloaded to local, which is $79.8 \%$.

According to the survey on the available learning resources (Table 1), 56.4\% of the students choose the professional learning resources, $54.8 \%$ are beneficial to their physical and mental health, $6.4 \%$ are rich in resources but troublesome to find, $73.7 \%$ are rich in resources but entertainment are in the majority, and that the resources are generally relatively smallis $3.2 \%$. Table 1 shows that although the number of mobile tools in hardware is relatively dominant, the corresponding software is not very sound. How to establish and improve the security and effectiveness of mobile learning resources, and how to build more learning resources repository closely linked to professional courses, is the main problem facing.

Table1. Resource utilization of students using mobile learning tools

\begin{tabular}{|l|l|l|l|}
\hline No. & Resource utilization of students using mobile learning tools & Number & Percentage \\
\hline 1 & Professional learning resources are relatively more. & 212 & 56.4 \\
\hline 2 & There are many kinds of physical and mental health development. & 206 & 54.8 \\
\hline 3 & More resources, but more trouble to find. & 24 & 6.4 \\
\hline 4 & There are many resources, but there are plenty of entertainment. & 277 & 73.7 \\
\hline 5 & Resources are generally relatively small. & 12 & 3.2 \\
\hline 6 & No resources & 0 & 0 \\
\hline
\end{tabular}




\subsubsection{Mobile Learning Content Selection}

As the construction of professional curriculum learning resources can not keep up with the pace of mobile learning theory and mobile learning tools, students' choice of mobile learning resources shows that (Fig. 5): the proportion of playing games for entertainment, watching movies and TV plays is the highest, accounting for $74.7 \%$. The number of students who chose Life Encyclopedia is $42.3 \%$. Only $35.6 \%$ of students are interested in mobile learning resources related to professional content. $9.3 \%$ of the students chose the qualification examination category. Only $6.1 \%$ students choose other contents. According to the above data, there is a serious shortage of mobile learning resources. In order to adapt to the current reform and development of Higher Vocational education, Higher vocational colleges, in the process of building of information of resource bank, should introduce more and more practical teaching resources to meet the students' choice of mobile learning content.

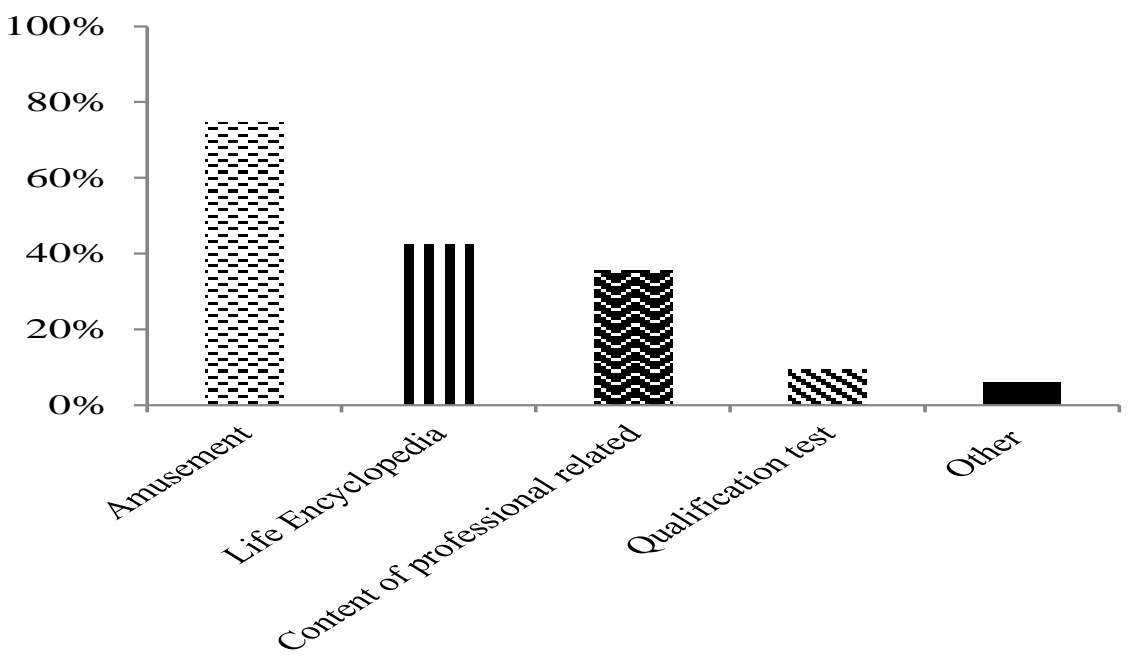

Figure5. Students' choice of mobile learning content

\subsection{The Effect of Using Mobile Learning Tools for Vocational Students}

From table 2, we can see how students respond to mobile learning. $67.2 \%$ of the students believe that, when use smartphone to learn, the goal is clear, which strengthens the daily learning effect. The test and evaluation of teachers' class can be timely feedback, so as to check leakage and fill it, and improve the learning efficiency. At the same time, resources such as audio and video, text materials and learning software on smartphones provide students with convenient learning content. $47.3 \%$ of students believe that it is helpful to consolidate and digest classroom knowledge. $82.1 \%$ of the students thought that teachers could get more and more abundant learning information and stimulate students' interest in learning when using mobile learning equipment in class. $78.4 \%$ of the students will faithfully preview the content of the new lesson on the mobile phone. Compared with traditional teaching, students can know the key points and difficulties of the new lesson, introduce the new content in advance to learn it, and transform passive learning into active learning. In addition, 34.6\% of the students took pictures of the teacher's courseware for review after class, only $1.1 \%$ of the students thought it had no effect.

Table2. The utilization of learning resources by students using mobile learning tools

\begin{tabular}{|l|l|l|l|}
\hline No. & Utilization evaluation & Number & Percentage \\
\hline 1 & $\begin{array}{l}\text { Learning objectives are clear, assessment is timely feedback, andleak } \\
\text { detection and compensation canimprove learning efficiency. }\end{array}$ & 253 & 67.2 \\
\hline 2 & $\begin{array}{l}\text { Providing convenient learning resources for students, and conducive to the } \\
\text { consolidation and digestion of classroom knowledge. }\end{array}$ & 178 & 47.3 \\
\hline 3 & $\begin{array}{l}\text { When mobile learning equipment are used to teach, the content is rich, } \\
\text { stimulating students' interest in learning. }\end{array}$ & 309 & 82.1 \\
\hline 4 & Preview in advance, easy to grasp the key and difficult points of the course. & 295 & 78.4 \\
\hline 5 & Take the teacher's courseware with mobile phone and review after class. & 130 & 34.6 \\
\hline 6 & No effect & 4 & 1.1 \\
\hline
\end{tabular}



Students

Table 3 shows that $100.0 \%$ of the students believe that mobile learning has the greatest advantage of being convenient to carry learning equipment and making full use of the full coverage of the school wireless network. $97.3 \%$ of the students believe that mobile learning can broaden their professional knowledge. $71.3 \%$ of the students believe that learning is more autonomous and they can control their learning progress. $70.2 \%$ of the students believe that mobile learning can broaden their professional knowledge. It strengthens and promotes the effect of curriculum learning.

Table3. Advantage of mobile learning

\begin{tabular}{|l|l|l|l|}
\hline NO. & advantage of mobile learning & Number & Percentage \\
\hline 1 & It can make full use of the full coverage of wireless network. & 376 & 100.0 \\
\hline 2 & Learning equipment is easy to carry. & 376 & 100.0 \\
\hline 3 & Broaden professional knowledge & 366 & 97.3 \\
\hline 4 & learning is more autonomous and they can control their learning progress & 268 & 71.3 \\
\hline 5 & strengthens and promotes the effect of curriculum learning & 264 & 70.2 \\
\hline 6 & No advantage & 0 & 0.0 \\
\hline 7 & Uncertain & 3 & 0.8 \\
\hline 8 & others & 2 & 0.5 \\
\hline
\end{tabular}

\section{CONCLUSION}

Mobile learning represents the learning style of the next generation, which started relatively late in our country. At present, it is still in the stage of exploration and research, and has not really spread to the teaching process of colleges and universities. Although it has the advantages of convenient use, easy access to resources, convenient interaction, but there are many problems when students use mobile learning tools to learn, especially in Vocational colleges, students' learning consciousness is low, self-control is poor, and there is a lack of systematic learning planning.

Based on the questionnaire survey on the application of mobile learning tools among students in Taizhou Vocational Colleges, the results show that mobile learning tools are mainly used for telephone and video, entertainment and social intercourse, accounting for more than $94 \%$, while only $29 \%$ are used for learning tools. Judging from the resources that students can choose to use, about $74 \%$ of the students chose entertainment, $56 \%$ choose professional learning resources, and about $36 \%$ of the students are interested in mobile learning resources related to the content of the profession.

It shows that although the number of mobile tools such as smart phones and notebook computers is predominant in hardware, the building of mobile learning resources in higher vocational colleges is seriously insufficient. How to establish and improve the security and effectiveness of mobile learning resources, and how to establish a library of learning resources closely related to the contents of professional courses are the problems facing us at present. It is also the main task of the current teaching reform and resource library building of higher vocational education, to introduce more practical learning resources, to meet the students' choice of mobile learning content for professional courses, to correctly guide students to apply mobile learning tools to daily learning, to cultivate their self-learning and self-control ability, so as to further enhance students' professional skills and comprehensive literacy.

\section{ACKNOWLEDGMENT}

This research was financially supported by Jiangsu University Philosophy and Social Sciences Research Foundation Project (Grant NO: 2017SJB1879).

\section{REFERENCES}

[1] SHAN Xin, HU Ying-yun, Current Situation and Development Trend of Mobile Learning. Journal of Hubei University of Education,2013, 8:49-52.

[2] He Jianwu.The application of mobile learning tools in college students' Autonomous English learning.

[3] Shaanxi Education (Higher Education), 2016,12:39.

[4] Fu jian, Yang xue. Ten years' research and practice of mobile learning theory in China. CET China Educational Technology. 2009,7:36-41.

[5] Chen ping. The plight and path choice of mobile learning for Higher Vocational Students under the background of new media -- Taking English learning as an example. Vocational \& Technical Education Forum. 2015,23:89-92. 
[6] JIANG Qiang,ZHAO Wei, WANG Peng-jiao. Cognitive Research of College Students'Mobile Learning based on Smart Phones under Fragmented Time. Modern Distance Education.2014,1:37-42.

[7] Li huanliang. Application status and Countermeasures of mobile learning in Higher Vocational Colleges. Master's thesis, Shandong Normal University.2012

[8] Huang Ronghuai.The present situation, theory and trend of mobile learning [M]. Beijing: Science Press.2008.

[9] Hu Lipan, Li Xincheng, Tang Guoju. Research status and development trend of mobile learning in China. China medical education technology.2011,3: 616-619

\section{AUTHOR's BIOGRAPHY}

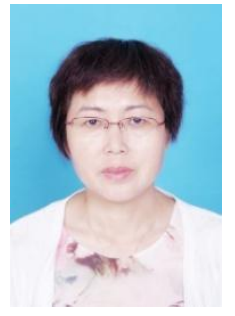

Zhang Cheng-xia, born in 1974, Female. Associate professor. Doctor degree. The research direction is practical research of higher vocational education and cultivation of innovative talents in modern agriculture.

Citation: Zhang Cheng-xia, et al "Investigation and Research on the Application of Mobile Learning Tools in Higher Vocational College Students " International Journal of Humanities Social Sciences and Education (IJHSSE), vol 5, no.9, 2018, pp. 37-42. doi: http://dx.doi.org/10. 20 431/2349-0381.0509006.

Copyright: (C) 2018 Authors. This is an open-access article distributed under the terms of the Creative Commons Attribution License, which permits unrestricted use, distribution, and reproduction in any medium, provided the original author and source are credited. 